the Fitness to Practise Policy Committee will play a major role in the final policy outcome decision. We at the British Association of Oral Implantology (BSOI) recognise the difficulties ahead and applaud the GDC in its attempts to ensure the public does not fall foul of the vagaries of advertising embellished by lists of letters designed to impress and coerce.

It is at this time that representative associations within dentistry need to take the lead in the provision of suggestions and ideas that will alleviate the current impasse and begin to push forward solutions that could maintain the academic hunger of dentists within the postgraduate arena and ensure such awards are recognised for their relevance to the practice of clinical dentistry.

The BSOI has drawn together a group of clinicians with expertise in the postgraduate clinical educational field and is dedicated to providing dentists with guidance required to satisfy the educational and clinical demands in postgraduate implant dentistry, to suit the requirements of all clinicians, particularly those in primary care. BSOI embraces all those involved in postgraduate training and has pledged to try and ensure uniformity in quality by collaboration between various postgraduate institutions, particularly those within the primary care sector. This collaboration could be the key to providing solutions for the GDC.

We feel that the GDC in conjunction with representative educational bodies could identify those standards required for award of an AQ within a particular field, which would be subject to regular review and revalidation. Those in the business of providing education would be made to produce these standards and report their agreed findings to the GDC. This is not a decision one association is capable of making; all representative parties should play a role. It would also be the duty of those representatives to police the education, training and assessment procedures.

Accordingly, the AQ attached to each clinical individual would have a level of recognition currently only attached to the BDS, would satisfy the GDC's desire to ensure that registers and information contained within IS of clear benefit to the public and would satisfy the requirement that any AQ identified with an individual had been rigorously quality assured. This is an opportunity and we recommend the GDC turns to the clinical arena for a solution to this dilemma.

S-J. Crean \& the Board of

The British Society of Oral Implantology DOI: 10.1038/sj.bdj.2008.472

\section{DON'T BE DOWNHEARTED}

Sir, fellow and prospective students taking the excellent and worldwide King's College MClinDent (Prosthodontics) degree by distance learning need not be too downhearted that it will not be recognised in the UK as an additional qualification. (Maclean J. Additional qualifications. BDJ 2008; 204: 420).

Many UK students do the residential part of the course at the dental school in Dharwad, Karnakata together with Indian and other international students. ${ }^{1}$ Therefore, the Dental Council of India has just recognised the MClinDent as India's second postgraduate degree alongside the MDS.

At least should we choose to practise in India our hard work would be acknowledged there!

M. W. Austin Hove

1. Austin M W. Star of India: the first MClinDent (prosthodontics) residential week in India. Br Dent J 2006; 200: 352-353.

DOI: 10.1038/sj.bdj.2008.474

\section{INCISOR TRANSPOSITION}

Sir, a 56-year-old male patient reporting for a routine dental check-up revealed right upper central and lateral incisors that had interchanged their positions (Fig. 1). The lateral incisor was slightly malformed (increased mesio-distal and cervico-incisal crown width) and the patient was totally unaware of the condition. An intraoral periapical radiograph revealed transposition of the upper right central and lateral incisors (Fig. 2). An incomplete dens in dente was observed in relation to the lateral incisor. Since the patient was not concerned with aesthetics and because of financial constraints no treatment was instituted.

Transposition has been described as an interchange of the position of permanent teeth and is considered to be a relatively rare dental anomaly. It was defined by
Peck et al. ${ }^{1}$ as the positional interchange of two adjacent teeth, particularly of the roots, or the development or eruption of a tooth in a position occupied normally by a non-adjacent tooth. The maxillary canine is the most commonly involved tooth $^{1-4}$ where in most of the cases it changes its eruptive place with a lateral incisor or a first premolar. The incidence of tooth transposition has been reported to be about $0.4 \% .^{2}$ Many articles have been published on the transposition of the maxillary canine with other teeth but to the best of our knowledge, only eight cases of transposition of a maxillary central incisor with a lateral incisor have been reported.

\section{A. A. Sholapurkar} Karnataka

1. Plunkett D J, Dysart PS, Kardos T B, Herbison G P. A study of transposed canines in a sample of orthodontic patients. Br J Orthod 1995; 25: 203-208.

2. Turkkahraman H, Sayin M D, Yilmax H H. Maxillary canine transposition to incisor site: a rare condition. Angle Orthod 2005; 75: 284-287.

3. Peck S, Peck L. Classification of maxillary tooth transpositions. Am J Orthod Dentofacial Orthop 1995; 107: 505-517.

4. Shapira Y. Transposition of canines. J Am Dent Assoc 1980; 100: 710-712.

DOI: 10.1038/sj.bdj.2008.473

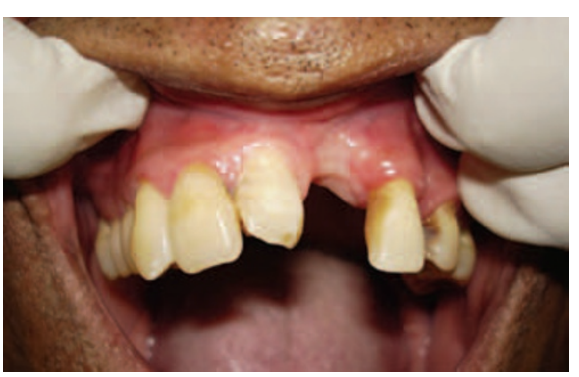

Fig. 1 Interchanged upper central and lateral incisors

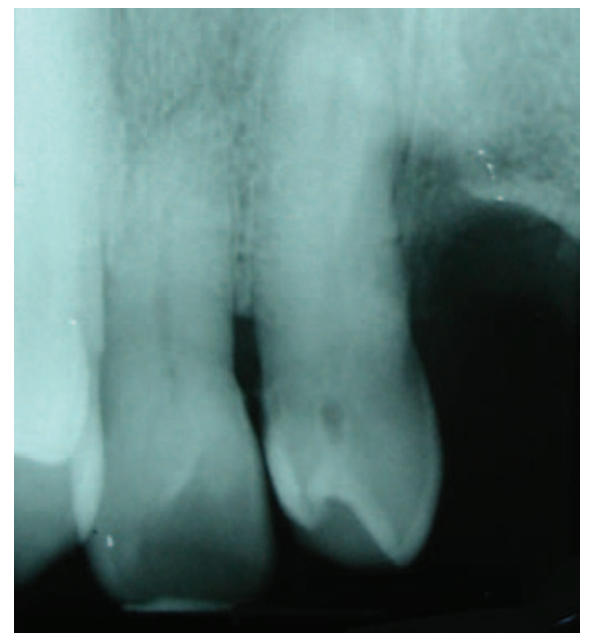

Fig. 2 Transposition of the upper right central and lateral incisors 